\title{
Phytochemical Screening and Antimicrobial Activity of Extracts of Iris nepalensis species Growing in Karnah Vallay, Kupwara, Jammu and Kashmir, India
}

\author{
Mohd Zakir ${ }^{1 *}$, Narendra Kumar ${ }^{2}$ \\ ${ }^{1}$ Research Scholar, Department of Biotechnology, Himalayan University, Ita Nagar, Arunachal Pradesh, India \\ ${ }^{2}$ Assistant Professor, Department of Botany, Alpine Institute of Management Technology, Dehradun, India
}

*Address for Correspondence: Mr. Mohd Zakir, Research Scholar, Department of Biotechnology, Himalayan University, Ita Nagar, Arunachal Pradesh, India

E-mail: dmzakirkhawaja13@gmail.com

Received: 06 July 2020/ Revised: 29 Sep 2020/ Accepted: 23 Dec 2020

\begin{abstract}
Background: In the Kashmir Himalaya, a region located in the northwestern extreme of the Himalayan biodiversity hotspot, the genus Iris occur from the valley bottom to high alpines along an altitudinal gradient ranging from 1600 to $4500 \mathrm{~m}$. Species of the genus Iris are recognized by their basal fan of unifacial leaves; colourful perianth of three horizontal sepals and three upright petals that are basally fused into a tube; style branches that are fused at the base, petaloid distally and extend beyond the small flap-like, and three stamens that are opposite to the sepals and petaloid style.

Methods: The fine dried (dried in shade) powder $(1 \mathrm{~g})$ of licorice leaves and root were used for the extraction of active ingredient $(5 \mathrm{ml})$. Acetone, methanol, ethanol and butanol were used as organic solvents for extraction. Phytochemical screening was performed of various phytochemicals in methanol extracts of an Iris plant and phytochemical tests were performed followed as Fehling's test and Keller-Kilani test as well as ferric chloride test, terpenoids and alkaloids test.

Results: Phytochemical analysis of chloroform, ethyl acetate and methanol extract of rhizomes of Iris nepalensis showed the presence of carbohydrate, alkaloids, flavonoids, phenolics, tannin, saponins, triterpenoids in Table 2,3 and 4.

Conclusion: Water, methanol and Ethanol extracts of the rhizome of Iris nepalensis were prepared and screened for phytochemical studies and antibacterial activities against bacterial strains including both Gram-positive and Gram-negative.
\end{abstract}

Key-words: Antibacterial activity, Iris nepalensis, Phytochemical screening, Plant extract

\section{INTRODUCTION}

Iris is the largest and most complicated genus of family Iridaceae ${ }^{[1]}$. The genus comprising of about 300 species is originated in Japan and the Mediterranean, however, the species of this plant are more concentrated in the south of the equator and very widely distributed throughout the North Temperate Zone ${ }^{[2]}$. About twelve species of genus Iris are found all over India ${ }^{[2-4]}$. Their habitats are considerably varied ranging from cold regions into the grassy slopes, meadowlands, the Middle East and northern Africa, Asia and across North America.

\section{How to cite this article}

Zakir M, Kumar N. Phytochemical Screening and Antimicrobial Activity of Extracts of Iris nepalensis species Growing in Karnah Vallay, Kupwara, Jammu and Kashmir, India. SSR Inst. Int. J. Life Sci., 2021; 7(1): 2754-2762.

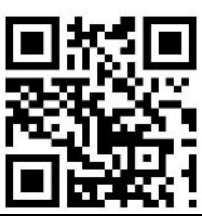

They are perennial herbs growing from creeping rhizomes (Rhizomatous Irises) or in drier climates from bulbs (bulbous Irises). They have long erect flowering stems, which may be simple or branched, solid or hollow, and flattened or have a circular cross-section. Many species of this genus have been used for long in medicine for their interesting biological activities. The peeled and dried rhizomes of Iris-species, collectively known as rhizome iridis enjoyed popularity due to their emetic, cathartic, diuretic stimulant and expectorant properties [2-4].

The genus comprising of about 300 species is originated in Japan and the Mediterranean. About twelve species of genus Iris are found all over India ${ }^{[2,5]}$. Their habitats are considerably varied ranging from cold regions into the grassy slopes, meadowlands, the Middle East and northern Africa, Asia and across North America. They are perennial herbs growing from creeping rhizomes 
(rhizomatous Irises) or in drier climates from bulbs (Bulbous Irises). The Iris plant has attracted considerable attention because of its antioxidant, Superoxide anion radical scavenging and cytotoxic properties ${ }^{[2,6]}$. Some Iris species are found in wetland environments. Iris is a perennial rhizomatous plant, growing to $30 \mathrm{~cm}$ high and widely distributed in most parts of the world ${ }^{[2-8]}$. Most species occur in the desert, semi-desert or dry, rocky habitats. Species of the genus Iris are recognized by their basal fan of unifacial leaves; colourful perianth of three horizontal sepals and three upright petals that are basally fused into a tube; style branches that are fused at the base, petaloid distally and extend beyond the small flap-like, transverse stigma as a bifid crest; and three stamens that are opposite to the sepals and petaloid style ${ }^{[8]}$. The most commonly grown plants and plants with medicinal use from the genus Iris species ${ }^{[9]}$.

In the Kashmir Himalaya, a region located in the northwestern extreme of the Himalayan biodiversity hotspot, the genus Iris occur from the valley bottom to high alpines along an altitudinal gradient ranging from 1600 to $4500 \mathrm{~m}$. Various species of Iris grow abundantly in diverse habitats such as alpine and subalpine meadows, roadsides, stream banks, public gardens, orchards, saffron fields, graveyards and cemeteries ${ }^{[10]}$.

From the Kashmir Himalaya, during over the last century, several workers while carrying out general floristic studies from different areas of the region have reported the occurrence of Irises species ${ }^{[2,10-11]}$. Because of the well-documented medicinal properties of various species of Iris and pharmacological effects of active constituents; the native species of Kashmir growing wild in Indian subcontinent also needs to be studied for their proper survey, identification, and bioprospection to harness its potential as a medicinal plant of therapeutic value ${ }^{[2]}$.

The state of Jammu and Kashmir of western Himalaya possesses about 2104 vascular plants that have acted as the source of natural remedies. Due to rich floral wealth; India is emerging an integral part of the global herbal market and could become the largest raw material supplier of herbal drugs ${ }^{[11,12]}$.

It is imperative for the current generation to scientifically explore floral diversity, design constructive strategies for sustainable utilization and conservation of forest flora, to conserve the natural heritage of flora for the future generations $^{[11-16]}$.
Nowadays, botanical and biochemical research brings new knowledge about chemical compounds in roots, leaves and flowers of the various medicinally important plant species. The present study establishes the biological characters of the selected plant species, their physicochemical values, and antimicrobial study of their plant-part extracts. The present study focuses on the evaluation of potent plant-part extract that could be used for antimicrobial activity on large scale.

\section{MATERIALS AND METHODS}

Survey and collection of plant materials- Survey was conducted in Karnah valley, Kupwara region situated at Kashmir valley in year 2018. The river Kishenganga, originating from the Himalayas, flows through the outer areas of the district from east to west. The district has a total geographical area of $2379 \mathrm{~km}^{2}$ and the study area lies between 340 45' and 750 20' east longitudes. The District is situated at an average altitude of 5300 feet from the sea level. The geographical area of the District is $2379 \mathrm{sq} . \mathrm{km}$.

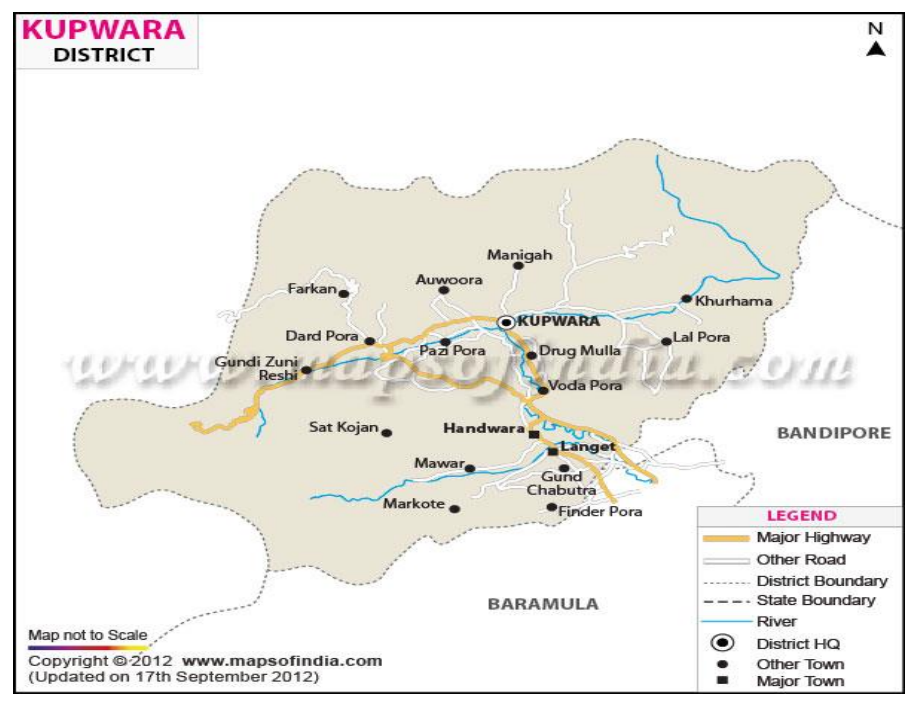

Fig. 1: Map of Kupwara region (not to scale)

Plant Materials- The rhizomes of $I$. nepalensis plant species were collected from the high altitudes of different authenticated voucher specimen has been deposited in the herbarium of KASH. Plant materials of species namely, I. nepalensis was collected as a whole plant locally, Karnah and Bungus valley situated at Karnah, District, Kupwara, regions of Kashmir valley, India during November-December 2018 and identification was done at Kashmir University Herbarium (KASH), Centre of Plant Taxonomy, Department of Botany, University of Kashmir, Srinagar, India. 


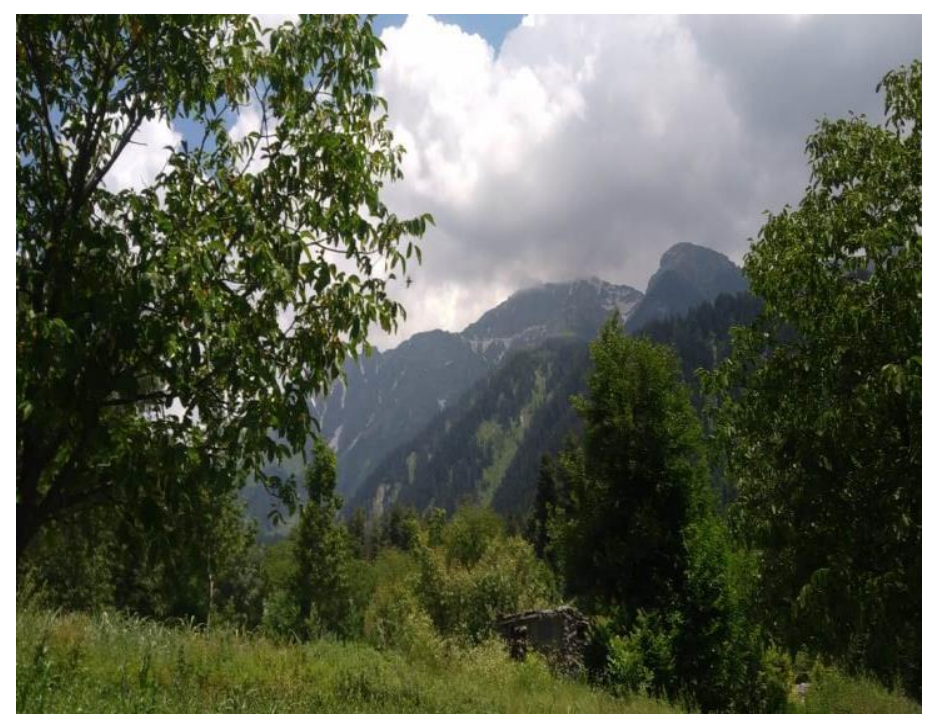

Fig. 2: Survey sites-Karnah Valley-Village-Nachiyan, Tehshil, Karnah District-Kupwara, J \& K

\section{Scientific classification}

Kingdom: Plantae

Clade: Tracheophytes

Clade: Angiosperms

Clade: Monocots

Order: Asparagales

Family: Iridaceae

Genus: Iris

Species: nepalensis

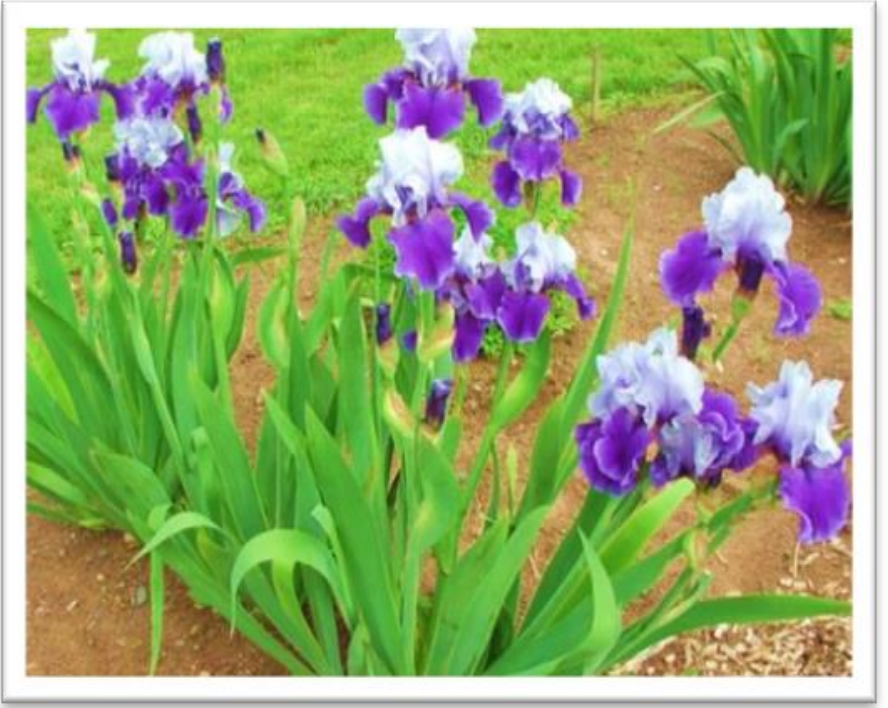

Fig. 3: Iris nepalensis plant

The genus Iris $L$. contains about 260 species, which are distributed in temperate regions across the Northern Hemisphere, occurring mostly in Eurasia and North America. Some Iris species are found in wetland environments, most species occur in the desert, semidesert or dry, rocky habitats. Species of the genus Iris are recognized by their basal fan of unifacial leaves; colourful perianth of three horizontal sepals and three upright petals that are basally fused into a tube; style branches that are fused at the base, petaloid distally and extend beyond the small flap-like, transverse stigma as a bifid crest; and three stamens that are opposite to the sepals and petaloid style ${ }^{[9,14,15]}$.

Chemical reagents- All the chemicals used in this study were obtained from HiMedia Laboratories Pvt. Ltd. (Mumbai, India), Sigma Aldrich Chemical Co. (Milwaukee, WI, USA), SD Fine-Chem Chem. Ltd. (Mumbai, India) and SRL Pvt. Ltd. (Mumbai, India). All chemicals and solvent used in this study were of analytical grade.

\section{Antimicrobial assay}

Preparation of Plant extract- The fine dried (dried in shade) powder ( $1 \mathrm{~g}$ ) of licorice leaves and root was used for the extraction of active ingredient $(5 \mathrm{ml})$. The organic solvents (acetone, methanol, ethanol and butanol) were used for extraction. The above mixture was vortexed for $1 \mathrm{hr}$ and then centrifuged at 10,000 rpm for $15 \mathrm{~min}$ at $25^{\circ} \mathrm{C}$. The liquid fraction was collected and used as the active ingredient for further applications. These extracts were dried under vacuum to obtain the active ingredient and were re-suspended insolvent with a final concentration of $0.2 \mathrm{~g} / \mathrm{ml}$. The continuous shaking was done until all the solutes have dissolved. The $\mathrm{pH}$ was adjusted at 7.2-7.5 with $1 \mathrm{~N} \mathrm{NaOH}$. The volume of the solution was adjusted to 1 litre with distilled water. The sterilization was done by autoclaving for $20 \mathrm{~min}$ at 15 $\mathrm{lb} / \mathrm{sq}$ and Solid NA media was used for streaking purpose. Liquid Nutrient agar media was used for the growing culture of the required strain.

Test organisms- The test microorganisms used in this study were (Bacterial sp.- E. coli, P. aeruginosa, Bacillus sp. and S. aureus; Fungi- Aspergillus niger, Candida albicans, Alternaria alternata and Clodisoprium sp.). These were provided by, Deptt. of Biotechnology, Himalayan University, Ita Nagar, Arunachal Pradesh, India.

Preparation of inoculum- The stocks of cultures were maintained at $4^{\circ} \mathrm{C}$ on nutrient agar slants. The bacterial cultures were inoculated on nutrient broth for overnight at $37^{\circ} \mathrm{C}$, while fungal cultures were inoculated on PDA 
(Potato Dextrose Agar). After appropriate growth, the healthy cultures were used for the antimicrobial assay.

Extraction of Plant materials- The dried parts of the plant were powdered and macerated. The extraction process of roots and leaves of the plants included first to dry the fresh plant by leaving it at room temperature for at least 7 days. After drying the leaves and root, they were then crushed into powder. 2gmof the roots and leaves powder was placed in $100 \mathrm{ml}$ water, which was boiled and then leaves it for I hour and filtered them into a flask by passing through Whatman No.1 filter paper ${ }^{[2,17]}$. Crude extraction with solvents including petroleum ether, ethyl acetate, chloroform, butanol and aqueous were carried out in soxhlet extractor to get the respective extracts which were later dried, weighed and kept for further usage in sterilized caped vials at $4^{\circ} \mathrm{C}$ $[2,18,19]$. The extract was then concentrated for storage to near dryness in low pressure at below 40oC through use of rotary evaporator. For storage of these extracts, they were diluted in about $20 \mathrm{mg} / \mathrm{ml}$ of $10 \%$ dimethyl sulfoxide solution and store in glass bottles which was airtight in a refrigerator for further studies ${ }^{[20-23]}$.

Phytochemical screening- To detect the presence of various phytochemicals in methanol extracts of an iris plant, phytochemical tests were performed by Wani et

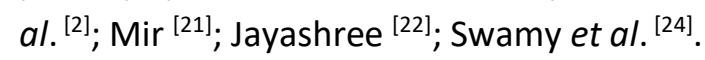

Flavonoids- In a test tube, contained $0.5 \mathrm{ml}$ of alcoholic extract added 5-10 drops of dilute $\mathrm{HCl}$ followed by a piece of $\mathrm{Zn}$ or $\mathrm{mg}$ and boiled the solution for few minutes, the pink or reddish-pink or brown colour produced indicated in the presence of flavonoids ${ }^{[25]}$.

Phenols (ferric chloride test)- Dissolved a small quantity of alcohol or aqueous extract in $2 \mathrm{ml}$ of distilled water and a few drops of $10 \%$ aqueous ferric chloride solution a blue or green colour is produced.

Saponins- Small quantity of alcoholic extract was mixed with some drops of sodium bicarbonate and leave for five minutes, the heavy comb-like froth was formed, confirmed in the presence of saponins.

Glycosides- Dissolved a small quantity of alcoholic extract after drying in $1 \mathrm{ml}$ of water and $\mathrm{NaOH}$ solution then yellow colour indicated of the presence of glycosides.
Tannins (ferric chloride test)- To 1-2 $\mathrm{ml}$ of extract added few drops of $5 \%$ aqueous ferric chloride solution, a bluish-black colour is produced, which disappears on the addition of few $\mathrm{ml}$ of the dilute sulphuric acid solution followed by the formation of a yellowish-brown precipitated, indicated of the presence of tannins ${ }^{[2]}$.

Qualitative phytochemical analysis preliminary qualitative phytochemical screening was carried out following standard protocols ${ }^{\text {[23-26] }}$.

Test for reducing sugars (Fehling's test) equal volume of Fehling $A$ and Fehling $B$ reagents were mixed and $2 \mathrm{ml}$ was added to the crude extract and gently boiled. A brick-red precipitate appeared at the bottom of the test tube indicated to the presence of reducing sugars. Test for glycoside $4 \mathrm{ml}$ of extract solution was dried till $2 \mathrm{ml}$. To it was added 1-2 $\mathrm{ml}$ of ammonium hydroxide and shaken. The appearance of cherish red colour indicated the presence of glycosides.

Keller-Kilani test crude extract was mixed with $2 \mathrm{ml}$ of glacial acetic acid containing 1-2 drops of $2 \%$ solution of $\mathrm{FeCl}_{3}$. The mixture was then poured into another test tube containing $2 \mathrm{ml}$ of concentrated $\mathrm{H}_{2} \mathrm{SO}_{4}$. A brown ring at the interface indicated the presence of cardiac glycosides.

Test for terpenoids crude extract was dissolved in $2 \mathrm{ml}$ of chloroform and evaporated to dryness. To this, $2 \mathrm{ml}$ of concentrated $\mathrm{H}_{2} \mathrm{SO}_{4}$ was added; a reddish-brown coloration at the interface indicated the presence of terpenoids.

Test for alkaloids crude extract was mixed with $2 \mathrm{ml}$ of $1 \% \mathrm{HCl}$ and heated gently. Mayer's and Wagner's reagents were then added to the mixture. Turbidity of the resulting precipitate was taken as evidence for the presence of alkaloids.

Test for coumarins extract solution was concentrated to yield a residue and dissolved the residue in hot water, after cooling divided solution in two test tubes. To one test tube added $10 \%(\mathrm{w} / \mathrm{v})$ ammonium hydroxide. Another test tube was used as a control. Fluorescence colour indicated the presence of coumarins.

Statistical Analysis- The change of colour was observed when the test reagent was added to the prepared sample for the phytochemical test. The result was recorded as present (+) or absent (-) depending on the outcome of the test. All experiments were done in triplicates. 


\section{RESULTS}

The crude extracts so obtained after the percolation extraction process, extracts were further concentrated on the water bath for evaporating the solvents completely to obtain the actual yield of extraction. To obtain the percentage yield of extraction is a very important phenomenon in phytochemical extraction to evaluate the standard extraction efficiency for a particular plant, different parts of the same plant or different solvents used. The yield of extracts obtained from the sample using chloroform, ethyl acetate and methanol as solvents are depicted in Table 1.

Table 1: Yield of rhizomes of $I$. nepalesnsis (\%) in different extract

\section{Extraction}

\section{Chloroform}

Ethyl acetate

Methanol

\section{I. nepalensis (\%)}

\subsection{2}

2.98

3.14
Result of the present study showed that methanolic extract of $I$. nepalensis has highest methanolic extractive percentage compare to other extracts. Phytochemical analysis of chloroform, ethyl acetate and methanol extract of rhizomes of $I$. nepalensis showed the presence of carbohydrate, alkaloids, flavonoids, phenolics, tannin, saponins, triterpenoids in Table 2,3 and 4.

Table 2: Phytochemical screening of rhizomes of $I$. nepalensis extracts

I. nepalensis extracts

\begin{tabular}{|c|c|c|c|}
\hline Tests & Chloroform & Ethyl acetate & Methanol \\
\hline \multicolumn{4}{|c|}{ Carbohydrate } \\
\hline Molish test & +ve & +ve & +ve \\
\hline Fehling test & $+v e$ & $+v e$ & $+v e$ \\
\hline Benedict test & $+\mathrm{ve}$ & tve & +ve \\
\hline \multicolumn{4}{|c|}{ Protein and Amino acids } \\
\hline Biuret test & -ve & -ve & +ve \\
\hline Ninhydrin test & -ve & -ve & $+v e$ \\
\hline \multicolumn{4}{|c|}{ Glycosides } \\
\hline Borntrager & -ve & & $+\mathrm{ve}$ \\
\hline Killarkillani & -ve & -ve & +ve \\
\hline \multicolumn{4}{|c|}{ Alkaloids } \\
\hline Mayer & +ve & +ve & +ve \\
\hline Hager & +ve & $+v e$ & +ve \\
\hline Wager & +ve & $+v e$ & +ve \\
\hline \multicolumn{4}{|c|}{ Saponins } \\
\hline Froth's test & -ve & -ve & $+v e$ \\
\hline \multicolumn{4}{|c|}{ Flavonoids } \\
\hline Lead acetate test & +ve & $+v e$ & +ve \\
\hline Alkaline reagent test & $+v e$ & + ve & $+v e$ \\
\hline \multicolumn{4}{|c|}{ Treterpenoids and Steroids } \\
\hline Salkowski's test & +ve & $+v e$ & +ve \\
\hline
\end{tabular}



L. burchard's test
+ve
+ve
+ve

Tannin and Phenolic Compounds

Ferric chloride test

-ve

$+\mathrm{ve}$

Lead acetate test

-ve

-ve

+ ve

Table 3: Phytochemical screening of the extracts of I. nepalensis Linn

\begin{tabular}{ccc}
\hline No & Test & Iris \\
\hline 1 & Saponin & + ve \\
2 & Tanin & + ve \\
3 & Steroid & - ve \\
4 & Flavonoid & - ve \\
5 & Terpenoid & + ve \\
6 & Napthoquione & - ve \\
7 & Insulin & - ve \\
8 & Phenol & + ve \\
9 & Carbohydrate & + ve \\
10 & Phlobatannin & - ve \\
11 & Starch & - ve \\
\hline
\end{tabular}

Table 4: Evaluation of antibacterial activity of aqueous extract of Iris nepalensis

\begin{tabular}{cc} 
Bacterial strains & IZD $(\mathbf{m m})$ \\
\hline S. aureus & $15 \pm 0.20$ \\
E. coli & $11 \pm 0.32$ \\
P. aeruginosa & $10 \pm 0.37$ \\
Proteus vulgaris & ND \\
Salmonella typhi & ND
\end{tabular}

*values are mean $\pm S E M, 3$ replicates/treatment. IZD= Inhibitory zone diameter $N D=$ Not detected

The chemical analysis of the plant extracts confide the presence of phytochemicals such as phenols, tannins, flavonoids, saponins, glycosides, steroids, terpenoids, and alkaloids, I. nepalensis is a plant rich in phenolic acid derivatives and flavonoids with notable antioxidant activity (Table 2 to 4), As far as we know the genus Iris wasn't examined broadly, which are known to exhibit medicinal as well as physiological activities? Various workers have reported the analgesic, antispasmodic and antibacterial ${ }^{[27]}$ properties of alkaloids. Glycosides are known to lower the blood pressure according to many reports ${ }^{[22,24,27]}$.
Phenolic compound possesses biological properties such as apoptosis, anti-ageing, anti-carcinogen, antiinflammation, anti-atherosclerosis, cardiovascular protection and improvement of endothelial function, as well as inhibition of angiogenesis and cell proliferation activities $^{[28]}$.

\section{DISCUSSION}

The plant extracts were also revealed to contain saponins which are known to produce an inhibitory effect on inflammation [2,27,28]. Steroids have been reported to have antibacterial properties ${ }^{[27,29]}$ and they 
are very important compounds especially due to their conformity with compounds such as sex hormones that results were followed as Epand et al. ${ }^{[29]}$; Sharanabasappa et al. ${ }^{[30]}$. The growth of many fungi, yeasts, bacteria and viruses can be inhibited by tannins was similarly findings

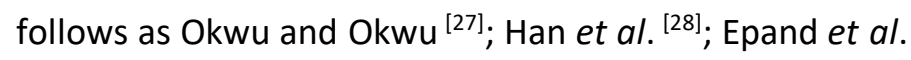

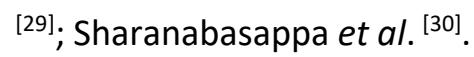

Although, the absence of certain phytochemicals in one sample and its presence in the other can be safely attributed to the various physiological and biosynthetic reactions taking place inside the plant, the effect of the environment should not be neglected, as the environment always modify the things. The preliminary phytochemical tests are therefore significant and helpful in finding chemical constituents in the plant material that may lead to their quantitative estimation and also in locating the source of pharmacologically active chemical compounds that finding similarly followed as Sharanabasappa et al. ${ }^{[30]}$. The results obtained in this study thus suggest the identified phytochemical compounds may be the bioactive constituents and these plants are proving to be an increasingly valuable reservoir of bioactive compounds of substantial medicinal merit that results similarly revealed as similarly as Shrestha et al. ${ }^{[26]}$.

The quantitative phytochemical assay was performed by calculating total phenolic content (TPC) and total flavonoid content (TFC). The TPC was calculated concerning gallic acid (standard) and the TPC in chloroform, ethyl acetate and methanol extract of rhizomes of $I$. nepalensis. In the present study, three different extracts viz, Ethanol, methanol and water extract of rhizomes of $l$. nepalensis species were prepared as per standard operating procedures. The Iris plant species selected were I. nepalensis which grow wild in Kashmir valley. The methanol extracts of the entire Iris species were subjected to phytochemical interpretation which revealed the presence of flavonoids, isoflavonoids, phenols, saponins, glycosides and tannins, while as alkaloids were absent. The different solvent extracts of the Iris species were screened for antibacterial activity against some bacterial pathogens viz, S. aureus, E. coli, $P$. aeruginosa, $P$. vulgaris and $S$. typhi using agar well diffusion method. The extracts exhibited a broad spectrum of antibacterial action with methanol extract of I. nepalensis showing the maximum zone of inhibition $(24 \pm 0.14 \mathrm{~mm})$ against $P$. aeruginosa.
The $P$. vulgaris strain was found to be resistant against all the extracts of the Iris species. The different extracts inhibited the growth of not only gram positive bacteria but also gram negative bacteria which most often show resistance to different antibacterial agents. Although this researches the Iris nepalensis is the species that is known for the highest accumulation of a large number of isoflavone similarly as Wani et al. ${ }^{[2]}$; Swamy et al. [24]; Krings and Berger ${ }^{[25]}$; Shrestha et al. ${ }^{[26]}$; Okwu and Okwu [27]; Han et al. ${ }^{[28]}$; Epand et al. ${ }^{[29]}$; Sharanabasappa et al. [30].

The antibacterial action of Iris extracts may be attributed to the presence of a variety of secondary metabolites including flavonoids, isoflavonoids and phenols which have already been reported to exert an antibacterial effect. Iris plant species was traditionally been used to treat a variety of infection. However very little is known about the mechanism by which these plant species mediate their specific effects. The present study was undertaken with the objective to estimation different solvent extracts of well-known Iris plant species for antibacterial action.

\section{CONCLUSIONS}

The current study dealed with the phytochemical screening and antibacterial activity of different extracts of $I$. nepelesnsis species growing in Kashmir valley J\&K, India. Anti-bacterial activities were shown against bacterial strains including both Gram-positive and Gramnegative. The different extracts inhibited the growth of not only gram-positive bacteria but also gram-negative bacteria, which most often show resistance to different antibacterial agents. The extracts exhibited a broad spectrum of antibacterial action with methanol extract of I. nepalensis was showing the maximum zone of inhibition $(24 \pm 0.14 \mathrm{~mm})$ against $P$. aeruginosa. The antibacterial action of distinct Iris extracts may be attributed to the presence of a variety of secondary metabolites including flavonoids, isoflavonoids and phenols, which have already been reported to exert antibacterial effect.

Therefore, I. nepalensis had traditionally been used to treat a variety of complication. However, very little is known about the mechanism by which these plant species mediated their distinct effects. 


\section{ACKNOWLEDGMENTS}

We are highly thankful to the staff of Department of biotechnology, Himalayan University, Ita Nagar, Arunachal Pradesh, India and Centre for Biodiversity \& Taxonomy, KASH, and the University of Kashmir for rendering help, both in field and herbarium, during the present study.

\section{CONTRIBUTION OF AUTHORS}

Research concept- Dr. Narendra Kumar

Research design- Dr. Narendra Kumar

Supervision- Dr. Narendra Kumar

Materials- Mohd Zakir

Data collection- Mohd Zakir

Data analysis and interpretation- Dr. Narendra Kumar

Literature search- Mohd Zakir

Writing article- Dr. Narendra Kumar

Critical review- Dr. Narendra Kumar

Article editing- Dr. Narendra Kumar

Final approval- Dr. Narendra Kumar

\section{REFERENCES}

[1] Choudhary D, Alam A. Pharmacology and Phytochemistry of Isoflavonoids from Iris Species; J Pharmacol Clin Res., 2017; 3(2): 001-06.

[2] Wani SH, Amin A, et al. Antibacterial And Phytochemical Screening of Different Extracts of Five Iris Species Growing in Kashmir. J Pharm Res., 2012; 5(6): 3376-78.

[3] Nazira N, Koulb S, Qurishia MA, Taneja SC, et al. New isoflavones from Iris kashmiriana. J Nat Pro Res., 2008; 10(12): 1137-41.

[4] Shaheen HA, et al. Distribution Pattern, Conservation Status, and Associated Flora of the Genus Juniperus in Subalpine Pastures of the Kashmir Himalayas; Mount Res Dev., 2021; 37(4): 487-93.

[5] Haq SM, Zubair A, Malik I, Rahman U. Quantification and characterization of vegetation and functional trait diversity of the riparian zones in protected forest of Kashmir Himalaya, India. Int J Bot Myco., 2019; 37: 11.

[6] Wani SH, Bhat HA, Mir Jl et al. Quantitative Analysis of Iridin in the Different Species of Iris Plant by Reverse Phase High Pressure Liquid Chromatography; Chem Sci Rev Lett., 2017; 6(24): 2202-07.
[7] Olga M, Volodumur K, Sergiy K, Anastasiia K. Isoflavonoids from the rhizomes of Iris hungarica and antibacterial activity of the dry rhizomes extract. Ars Pharm., 2017; 58(1): 39-45.

[8] Wilsom CA. Sub generic classification in Iris reexamined using chloroplast sequence data. Taxon., 2001; 60 (1): 27-35.

[9] Kassak P. Secondry metabolites of the choosen genus species: Acta Universits Agri et Brunensis; LX., 2012; 32(8): 269-80.

[10]Zeerak NA, Wani SA. Diversity of Irises from Kashmir Himalaya. J Ornamental Horticul., 2007; 10(2): 11518.

[11]Dar GH, Khumroo AA. Floristic Diversity in the Kashmir Himalaya: Progress, Sains Malaysiana., 2013; 42(10): 1377-86.

[12]Chesfeeda A, Khuroo A, Malik AH, Dar GH. A taxonomic appraisal of genus Iris I. (iridaceae) in kashmirhimalaya, India. Iran J Bot., 2013; 19(1): 11926.

[13] Kachroo P, Sapru BL, Dhar U. Flora of Ladkah. Bishen Singh Mahendra Pal Singh, 1997.

[14]Parveen S. In vitro studies of some medicinal plants of western Himalayas viz Rheum emodi, Bergenia ligulata, Lavatera cashmiriana. Ph.D. Thesis Submitted to University of Kashmir, Srinagar, 2013.

[15]Dar GH, Bhagat RC, Khan MA. Biodiversity of Kashmir Himalaya Valley book house, Srinagar Kashmir, J \& K, 2002.

[16]Kumar N, Wani ZA, Dhyani S. Ethanobotanical Study of plants used by the local people of Gulmarg and its allied areas, J \& K, India. Int J Cu Res Biosc Biol., 2015; 2(9): 16-25.

[17]Barnes MA, Turner CR, Jerde CL. Environmental conditions influence DNA persistence in aquatic systems. Env Sci and Tech., 2014; 48: 1819-27.

[18]Farooq S, Roohi M, Bhat ZA. Preliminary phytochemical screening of Iris kashmiriana Baker collected from Budgam, Kashmir, India. J Drug Deli Therap, 2019; 9(1): 121-24.

[19]Mingarro DM, Acero N, et al. Biological activities from Catalpa bignonioides Walt. (Bignoniaceae). J Ethno pharmacol., 2003; 87: 163-67.

[20]Tiwari P, Kumar BK, et al. Phytochemical screening and extraction: A review. Int Pharm Sci., 2011; 1(1): 98-106. 
[21]Mir AH. Pharmacological and Phytochemical Properties of Iris Kashmiriana Baker As A Potential Medicinal Plant Of Kashmir Himalaya. G J Res Med P Indig Med., 2014; 3(12): 460-66.

[22]Jayashree BS. Isolation of Isoflavones from Iris Kashmiriana Baker as Potential Anti Proliferative Agents Targeting NF-kappa B. Phytochem., 2017; 136 (1): 70-80.

[23]Tiwari P, Kumar B, Kaur M, Kaur G, Kaur H. Phytochemical screening and extraction: A review. Int Pharm Sci., 2011; 1(1): 98-106.

[24]Swamy NT, Rosaiah G, Babu K, Kumar KV. A study on phytochemical composition, GC-MS analysis and anti-microbial potential of methanolic leaf extract of Alstonia scholaris (L.) R. Br. Int J Pharm Sci Res., 2019; 10(3): 747-55.

[25]Krings U, Berger RG. Antioxidant activity of some roasted foods. Food Chem., 2001; 84: 329-39.
[26] Shrestha P, Adhikari S, Lamichhane B, Shrestha G. Phytochemical Screening of the Medicinal Plants of Nepal. IOSR-JESTFT, 2015; 1(6): 11-17.

[27]Okwu D, Okwu M. Chemical composition of Spondias mombin linn. Plant parts. J Sust Agri Env., 2004; 6(2): 140-47.

[28] Han X, Shen T, Lou H. Dietary Polyphenols and Their Biological Significance, IJMS, 2007; 8(9): 950-88.

[29] Epand R, Savage P, Epand R. Bacterial lipid composition and the antimicrobial efficacy of cationic steroid compounds (Ceragenins), Biochimica Et Biophysica Acta (BBA)-Bio Membranes, 2007; 1768(10): 2500-09.

[30]Sharanabasappa G, Santosh M, et al. Phytochemical Studies on Bauhinia racemosa Lam. Bauhinia purpurea Linn. and Hardwickia binata Roxb. J Chem., 2007; 4(1): 21-31. 